\title{
Spatial distribution and sampling of Corythucha ciliata (Hemiptera: Tingidae) in London plane trees
}

\author{
He-Ping Wei, Feng Wang* \& Rui-Ting Ju
}

\begin{abstract}
Wei, H.-P., Wang, F. \& Ju, R.-T. 2013: Spatial distribution and sampling of Corythucha ciliata (Hemiptera: Tingidae) in London plane trees. - Entomol. Fennica 24: 43-52.
\end{abstract}

Taylor's power law and Iwao's patchiness regression were used to describe the dispersion patterns for overwintering and wandering stages of Corythucha ciliata on the London plane trees, Platanus $\times$ acerifolia (Ait.) Willd. Both Taylor's and Iwao's tests fit the distribution data for the overwintering stage. The overwintering adults were spatially aggregated. In the wandering stage, Taylor's power law consistently fit the data, whereas the fit of Iwao's patchiness regression was erratic. Both Iwao's and Taylor's indices indicated a clumped distribution pattern for eggs, nymphs, and wandering adults. Trunk was identified as the best sampling target for the overwintering stage whereas twig was the best for the wandering stage. In order to determine the sample size for evaluating whether the population has reached the control threshold, the sampling of 35 and 7 trunks for the overwintering stage and 32 and 8 twigs per tree for the wandering stage would provide 0.5 - and 0.25 -precision levels, respectively.

H.-P. Wei, School of Life Sciences, Anqing Teachers College, Anqing 246011, Anhui, P. R. China

F. Wang* \& R.-T. Ju, Department of Plant Protection, Shanghai Institute of Landscape Gardening Science, No. 899 Longwu Road, Xuhui District, Shanghai 200232, P. R. China; *Corresponding author's e-mail:wf5257@sina.com

Received 9 July 2012, accepted 5 November 2012

\section{Introduction}

The sycamore lace bug, Corythucha ciliata (Say) (Hemiptera: Tingidae), is a relatively recent, invasive, and exotic pest of Platanus trees (Platanaceae) in China ( $\mathrm{Ju} \& \mathrm{Li} 2010)$. This herbivore originated from North America (Halbert \& Meeker 1998) and is now widely spread in many countries throughout Europe (Maceljski 1986, Mutun 2009), South and North America (Halbert \& Meeker 1998), Australia, and Asia (Chung et al. 1996, Ju et al. 2009, Ju \& Li 2010). In China, C. ciliata was first reported in 2002 in Changsha of Hunan Province (Streito 2006), and was reported in 11 other provinces (Shanghai, Zhejiang,
Anhui, Jiangsu, Guizhou, Sichuan, Chongqing, Hunan, Hubei, Henan, and Shandong) over the last decade (Ju et al. 2009, Ju \& Li 2010). It causes serious damage in the Yangtze River basin, and particularly in Shanghai, Jiangsu and Hubei where almost $70 \%$ of the host trees are currently infested (Ju et al. 2009).

Corythucha ciliata has a short life cycle and it is oligophagous. Its hosts, Platanus spp., are widely distributed in China, because they are commonly planted along city streets (Ju et al. 2010a, 2011a). The insect completes five generations per year in Wuhan and Shanghai, with five immature instars per generation (Xia et al. 2007, Xiao et al. 2010, Ju et al. 2011a). Its piercing and 
Table 1. Locations with plot numbers, approximate tree ages (years) and months of investigation in 2010 of Corythucha ciliata.

\begin{tabular}{llcl}
\hline Plot & Location in Shanghai & Tree age & Month \\
\hline 1 & Zhaojiabang Road, Xuhui District & 50 & February \\
2 & People Square, Huangpu District & 50 & March \\
3 & Renmin Park, Huangpu District & 50 & February \\
4 & West Yan'an Road, Changning District & 50 & March \\
5 & Dongfang Road, Pudong District & 45 & March \\
6 & Longwu Road, Xuhui District & 50 & July \\
7 & West Longhua Road, Xuhui District & 50 & August \\
8 & Qiujing Road, Songjiang District & 50 & August \\
\hline
\end{tabular}

sucking feeding habits initially cause white stippling on the leaves, which reduces photosynthesis and respiration and also reduces the aesthetic value of the trees (Ju et al. 2010b). The stippled foliage then becomes chlorotic and bronzed, and the affected trees experience premature leaf drop (Halbert \& Meeker 1998). Several years of severe damage by $C$. ciliata combined with the effects of other environmental stresses may kill the host trees (Halbert \& Meeker 1998).

Because of serious damage caused by $C$. ciliata in many parts of the world, the pest has been frequently studied. Researchers have investigated its geographical spread (Öszi et al. 2005, Chung et al. 1996, Mizuno et al. 2004, Li et al. 2008), population dynamics (Öszi et al. 2005), biological characteristics (Battisti et al.1985, Cheol \& Kwang 2000, Xia et al. 2007, Ju et al. 2010a), thermal tolerance (Ju et al. 2010c, 2011b, c), natural enemies (Balarin \& Maceljski, 1986a,b), and control (Jasinka \& Bozsits 1977, Jasinka 1981, Wicki 1984, Reiderné \& Ripka 1990, Cheol \& Kwang 2000). Management of C. ciliata includes repeated applications of organophosphorous, synthetic pyrethroid, imidacloprid, thiamethoxam, or acetamiprid insecticides (Ju et al. 2009, Xiao et al. 2010, Chen et al. 2011). Basic information concerning $C$. ciliata ecology, however, remains insufficient. Because efficient pest control requires basic ecological information, more studies on C. ciliata ecology are needed.

The spatial distribution of a pest is one of its most important ecological properties (Taylor 1984), and information concerning spatial distribution is essential for pest management in the field (Bechinski \& Pedigo 1981). The objectives of this paper were: (1) to determine the distribution pattern of various stages of $C$. ciliata among and within London plane trees, and (2) to determine the optimal sampling units for estimating C. ciliata population densities.

\section{Material and methods}

\subsection{Location and investigation periods}

Corythucha ciliata populations were examined on London plane trees, Platanus $\times$ acerifolia (Ait.) Willd., at eight locations or plots (Table 1) in Shanghai, China $\left(31.2^{\circ} \mathrm{N}, 121.5^{\circ} \mathrm{E}\right)$ during two periods in 2010: February-March (adults were overwintering) and July-August (adults and nymphs of the second and third generations were in their wandering stage). Each of the eight plots contained $100-120$ trees.

\subsection{Distribution patterns of overwintering adults}

Adult C. ciliata overwinters under the bark of their host (Xia et al. 2007). To explore the population distribution pattern for overwintering adults, trees in five plots (plots $1-5$ in Table 1) were sampled. The trees in these plots were about $8-10 \mathrm{~m}$ tall, about $20-25 \mathrm{~cm}$ in diameter at breast height, and were not treated with pesticide or pruned during the sampling period. In each plot, eight trees were randomly selected, and samples were collected separately from the trunk and from the branches of each tree. The adults were collected by removing all of the barks on the trunk 
from the soil surface to the first branch and by removing all the barks from all the branches for a distance of $50 \mathrm{~cm}$ from the trunk. The adults were counted separately for trunk and branches.

Means and variances of $C$. ciliata numbers were calculated from tree-specific numbers of 40 trees, based on bug numbers on trunks and their numbers on branches. The means were compared with a t-test $(P<0.05)$. The analyses were performed with the statistical package SPSS NLN, 13.0 (SPSS 2006).

\subsection{Distribution patterns for eggs, nymphs, or wandering stage adults}

To explore the population distribution pattern for eggs, nymphs, and wandering adults, trees in three plots (plots 6-8 in Table 1) were sampled. These trees were about 8-10 m tall, about 20-25 $\mathrm{cm}$ in diameter at breast height, and they were also not treated with pesticide or pruned during the sampling period. From each plot, 10 trees were randomly selected, and the canopy of each tree was divided into an upper layer (that received substantial sun light) and a lower layer (that was shaded). Both layers were divided into four directions (east, west, south, and north). Four twigs were cut out from every direction. Each twig bore ten leaves. The numbers of the eggs, nymphs, and adults were counted per leaf, per twig, per layer, and per tree (based on 8 twigs and 80 leaves per layer and 16 twigs and 160 leaves per tree). Adults and nymphs were observed directly and eggs were detected with a dissecting microscope. The twigs were placed into a plastic bag for bringing to the laboratory. They were stored at $5{ }^{\circ} \mathrm{C}$ and examined within two days.

Statistical analyses were the same as described in the previous section, but the means were compared with the Tukey's test $(P<0.05)$ (SPSS 2006).

\subsection{Analysis of spatial distribution}

Analysis of the spatial distribution of overwintering adults was based on the means and variances of the numbers per tree, per trunk, and per branch. Analysis of the spatial distribution of eggs, nymphs, and the wandering stage of adults was based on the means and variances of the numbers per tree, per twig, and per leaf. Two classical dispersion models, i.e., Taylor's power law (Taylor 1961) and Iwao's regression (Iwao 1968), were used to evaluate the distribution of $C$. ciliata among the different parts of the tree.

The formula for Taylor's power law is:

$s^{2}=a m^{b}$

where $s^{2}$ is the variance of insect numbers in the sampling unit, $\mathrm{m}$ is the mean number of the insects in the sampling unit, a is the sampling factor that changes with the sampling unit, and $b$ is the dispersion index of a certain species. The population has a random or Poisson distribution when $s^{2}$ $=m$, a uniform distribution when $s^{2}<m$, and an aggregated distribution when $s^{2}>m$ (Yamamura 2000). The coefficients $a$ and $b$ were estimated from the following equation (Southwood 1978):

$\log ^{2}=\log a+b(\log m)$

Iwao's patchiness regression was simulated by the following equation (Iwao 1968):

$M^{*}=\alpha+\beta m$

where $M^{*}$ is the mean crowding, $\alpha$ is the index of basic contagion and $\beta$ is density-contagiousness coefficient. When $\alpha=0$, a single individual is the basic component of the distribution, and when $\alpha$ $>0$ or $\alpha<0$, there is a positive or negative association between individuals. The density-contagiousness coefficient $(\beta)$ indicates how the basic components are distributed in space. When $\beta<1$, the distribution is regular; when $\beta=1$, the basic components are randomly distributed and when $\beta$ $>1$, the basic components are distributed contagiously (Iwao 1968).

The mean crowding $M^{*}$ was derived from Lloyd's formula (Lloyd 1967):

$M^{*}=m+S^{2} / m-1$

where $s^{2}$ and $m$ were substituted by the variance and mean, respectively, of the insects in the sampling unit. 
Table 2. Taylor's power law and Iwao's patchiness regression indices for overwintering adults of Corythucha ciliata among trees, trunks, and branches.

\begin{tabular}{|c|c|c|c|c|c|c|}
\hline \multirow[t]{2}{*}{ Sampling unit } & \multicolumn{3}{|c|}{ Taylor's power law } & \multicolumn{3}{|c|}{ Iwao's patchiness regression } \\
\hline & $m$ & $S^{2}$ & $R^{2}$ & $\alpha$ & $\beta$ & $R^{2}$ \\
\hline Among trees & $1.13-87.25$ & $2.98-7849.64$ & $0.99^{* *}$ & 1.75 & 2.00 & $1.00^{* *}$ \\
\hline Among trunks & $0.38-47.88$ & $0.55-3627.84$ & $0.99^{* *}$ & -0.78 & 2.55 & $1.00^{* *}$ \\
\hline Among branches & $0.75-39.38$ & $1.93-1978.84$ & $0.99^{* *}$ & -0.15 & 2.26 & $1.00^{* *}$ \\
\hline
\end{tabular}

** Significance with $P<0.001$ by linear regression.

\subsection{Selecting the appropriate sampling unit and sampling stage}

For the overwintering stage, the appropriate sampling unit, i.e., either branches or trunks, was determined based on the adult numbers per trunk or per branch. The part of the tree with the higher insect density was selected as the sampling unit.

For the eggs, nymphs, and wandering stage of adults, the twigs growing in a specific layer (upper or lower) and in a specific direction (east, south, west, or north) with the highest insect density were regarded as the appropriate sampling unit.

The "appropriate representative sampling stage" was then determined by correlation of each developmental stage to the whole population (i.e. the total of eggs, nymphs and adults). A specific developmental stage, whose numbers were best correlated with the total numbers of insect individuals on each twig, was chosen as the appropriate representative sampling stage.

\subsection{Sample size}

After the best regression model was determined, two methods were used to calculate the number of samples required to estimate the mean with a given level of precision.

(1) Iwao and Kuno (1968) and Kuno (1969) presented a sample size method that applied $\alpha$ and $\beta$ indices from Iwao's regression to determine the optimal number of samples $(N)$ for estimating the mean density $(m)$ with a given level of precision $(D)$. The equation for this method is:

$N=[(\alpha+1) / m+(\beta-1)] / D$

(2) Wilson and Room (1982) incorporated $a$ and $b$ indices derived from Taylor's power law to calculate the optimal number of samples $(N)$ necessary to estimate the mean density $(m)$ with a given level of precision $(D)$. Their equation is:

$N=\left(Z_{\alpha / 2} / D\right)^{2} \times(S / m)^{2}$

where $Z$ is the standard normal deviate (Type I error rate $(\alpha)=0.1$, then $Z$ is 1.64 in two tails with $d f$ $=\infty$ ). Before sampling in the field, precision levels $(D)$ were set as 0.25 and 0.5 for both of these methods. Then optimal numbers $(N)$ were calculated. For example, when $N=500$ and $D=0.25$, then the actual number cannot be greater than 625 (i.e. $500 \times 0.25+500$ ) or less than 375 (i.e. $500-$ $500 \times 0.25)$.

\section{Results}

\subsection{Spatial distribution}

As shown in Table 2 for overwintering adults, in Taylor's law, all $s^{2}$ were higher than $m$, and Iwao's indices of dispersion $(\beta)$ were above 1 among trees, trunks and branches. These data indicated that overwintering adults were aggregated among all the studied sampling levels. Both Taylor's power law regression and Iwao's patchiness regression fit the linear law (Taylor's: $R^{2}=$ 0.99; Iwao's: $R^{2}=1.00$; for both $P<0.001$ ).

For the eggs, nymphs and wandering-adult stages of $C$. ciliata, both indices also indicated that all the three stages were aggregated $\left(S^{2}>m\right.$ for Taylor's, $\beta>1$ for Iwao's). In linear regressions, Taylor's power law fit the data more consistently than Iwao's patchiness regression (Taylor's: $R^{2}=0.88-0.99$; Iwao's: $R^{2}=0.51-1.00$; for both $P<0.001$ ) (Table 3 ). 
Table 3. Taylor's power law (A) and Iwao's patchiness regression (B) for Corythucha ciliata eggs, nymphs, and adults (wandering stage) on trees, twigs, and leaves.

A. Taylor's power law

\begin{tabular}{lllll}
\hline Sampling unit & $\begin{array}{c}\text { Developmental } \\
\text { stage }\end{array}$ & \multicolumn{1}{c}{$m$} & \multicolumn{1}{c}{$S^{2}$} & $R^{2}$ \\
\hline Among trees & Egg & $420.10-928.00$ & $72853.21-195773.33$ & $0.99^{* *}$ \\
& Nymph & $123.60-192.50$ & $5516.93-9733.79$ & $0.88^{* *}$ \\
Among twigs & Adult & $53.50-209.20$ & $3332.50-12533.95$ & $0.99^{* *}$ \\
& Egg & $13.90-156.80$ & $475.21-23078.18$ & $0.97^{* *}$ \\
& Nymph & $6.80-27.40$ & $66.18-1597.57$ & $0.92^{* *}$ \\
Among leaves & Adult & $2.70-37.20$ & $5.56-751.96$ & $0.96^{* *}$ \\
& Egg & $0.10-25.79$ & $0.22-1265.13$ & $0.98^{* *}$ \\
& Nymph & $0.30-4.55$ & $1.33-161.46$ & $0.96^{* *}$ \\
& Adult & $0.11-4.85$ & $0.18-55.02$ & $0.97^{* *}$ \\
\hline
\end{tabular}

** Significance with $P<0.001$ by linear regression.

B. Iwao's patchiness regression

\begin{tabular}{lllll}
\hline Sampling unit & $\begin{array}{c}\text { Developmental } \\
\text { stage }\end{array}$ & $\alpha$ & $\beta$ & $R^{2}$ \\
\hline Among trees & Egg & 171.31 & 1.04 & $1.00^{\text {** }}$ \\
& Nymph & 52.37 & 1.02 & $0.97^{* *}$ \\
Among twigs & Adult & 55.07 & 1.03 & $1.00^{* *}$ \\
& Egg & -514.65 & 22.87 & 0.51 \\
& Nymph & 8.59 & 1.77 & $0.86^{* *}$ \\
Among leaves & Adult & 3.77 & 1.36 & $0.94^{* *}$ \\
& Egg & 16.25 & 1.23 & $0.69^{* *}$ \\
& Nymph & 11.65 & 2.57 & $0.69^{* *}$ \\
& Adult & 3.83 & 2.77 & $0.85^{* *}$ \\
\hline
\end{tabular}

** Significance with $P<0.001$ by linear regression.

Table 4. Numbers of Corythucha ciliata eggs, nymphs, and wandering adults per twig (mean $\pm S E$ ) in relation to tree layer and branch direction.

\begin{tabular}{|c|c|c|c|c|}
\hline Layer & Direction & Eggs & Nymphs & Adults \\
\hline \multirow[t]{4}{*}{ Upper } & East & $19.6 \pm 15.1$ & $11.7 \pm 7.6$ & $51.6 \pm 16.9$ \\
\hline & South & $20.8 \pm 15.5$ & $12.0 \pm 7.4$ & $52.0 \pm 18.7$ \\
\hline & West & $22.4 \pm 17.7$ & $11.5 \pm 6.7$ & $49.0 \pm 18.8$ \\
\hline & North & $22.6 \pm 16.2$ & $10.3 \pm 5.2$ & $53.2 \pm 17.4$ \\
\hline \multirow[t]{4}{*}{ Lower } & East & $21.5 \pm 17.4$ & $12.6 \pm 6.2$ & $51.3 \pm 17.1$ \\
\hline & South & $19.6 \pm 16.7$ & $12.3 \pm 8.4$ & $54.1 \pm 18.0$ \\
\hline & West & $20.7 \pm 15.7$ & $13.9 \pm 9.3$ & $49.9 \pm 17.5$ \\
\hline & North & $18.3 \pm 17.7$ & $12.2 \pm 9.1$ & $50.2 \pm 16.8$ \\
\hline
\end{tabular}

Values within a column are not significantly different (Tukey's test: $P<0.05$ ). 


\subsection{Selection of the appropriate sampling unit and sampling stage}

In the overwintering stage, $59 \%$ of the adults were on trunks and $41 \%$ were on branches. Adult densities were significantly higher on trunks (45.76 \pm 9.56 per trunk) than on branches (34.12 \pm 9.78 per branch $)\left(t_{39}=10.03 ; P<0.0001\right)$. Thus, the trunk was used as the sampling target for investigating the distribution of overwintering adults.

For eggs, nymphs, and wandering adult stages of $C$. ciliata, densities on twigs were not significantly affected by the layer of the canopy $\left(\mathrm{F}_{1,239}=0.19-3.09, P=0.17-0.69\right)$ or by the direction $\left(\mathrm{F}_{2,239}=0.31-3.76, P=0.15-0.81\right)$ (Table 4). Thus, twigs were used as the sampling target without regard to layer or direction.

To determine the representative developmental stage for the sampling unit during the wandering period, the numbers of each developmental stage were regressed against the total numbers of all stages from each twig. The regression coefficient was much higher for adults $\left(R^{2}=0.92\right)$ than for other stages (Fig. 1), which indicated that adult stage could be recommended as the sampling target for representing $C$. ciliata populations in field investigations during the wandering period.

\subsection{Sample size}

For the overwintering adults, both Taylor's power law regression and Iwao's patchiness regression fit the data well. Here, we estimated the optimal sample size according to the assumption of Iwao's regression. The $\alpha$ and $\beta$ indices of the target sampling unit (trunks) were -0.78 and 2.55 , respectively. Based on Equation (5), the optimal number of trunks that should be sampled for a given number of overwintering adults per trunk is indicated in Fig. 2a. Öszi et al. (2005) reported that 48 overwintering adults per trunk would cause serious damage to the tree in late spring. According to the Technical Regulation of the Shanghai Gardening Plant Protection (TRSGPP) published by the Shanghai Administration Department of Afforestation in 2007, controls should be applied when the number of adults
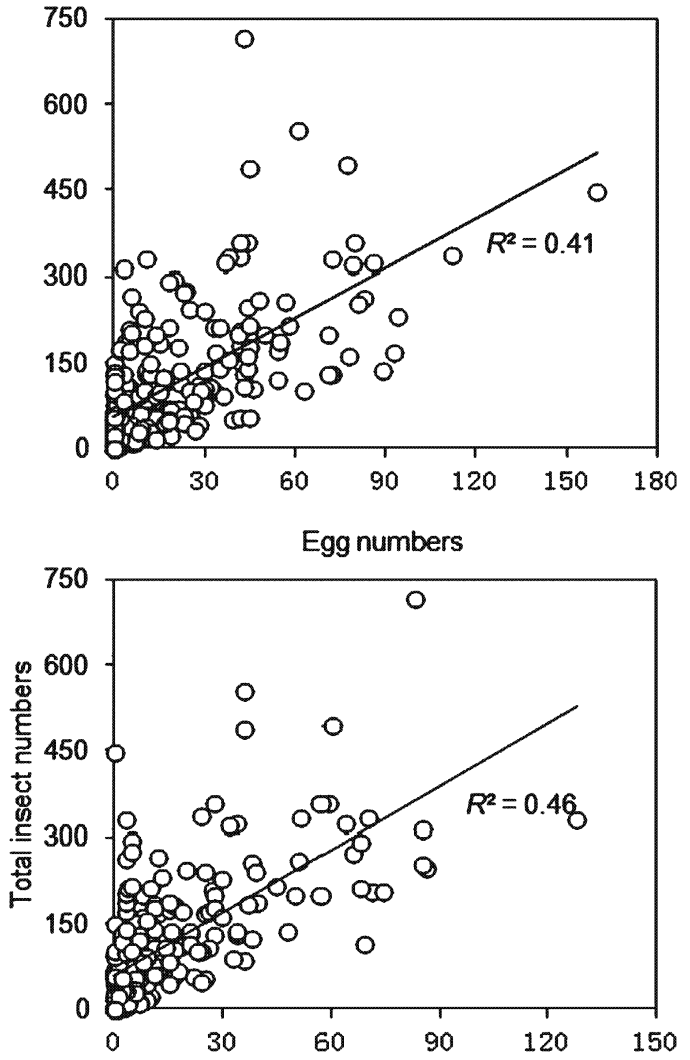

Nymph numbers

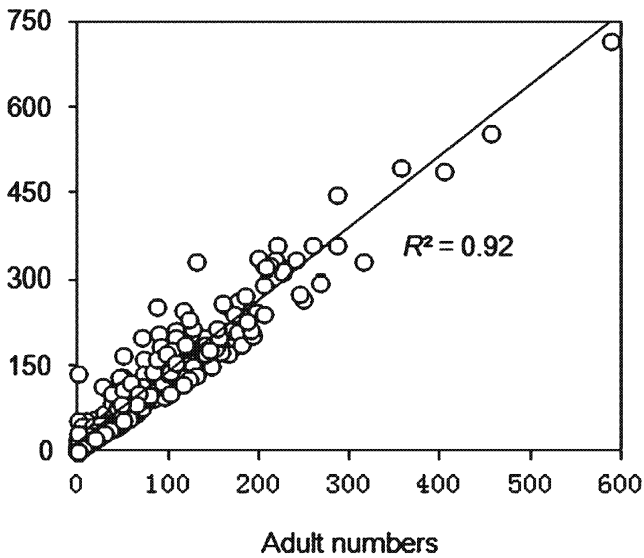

Fig. 1. Linear regressions of sample mean densities of different stages during wandering period against total numbers (sum of all stages) of Corythucha ciliata on London plane trees.

reaches one-quarter of the damaging level, i.e., when there are 12 overwintering adults per trunk. In Shanghai, therefore, estimating the number of overwintering adults per trunk with a precision 

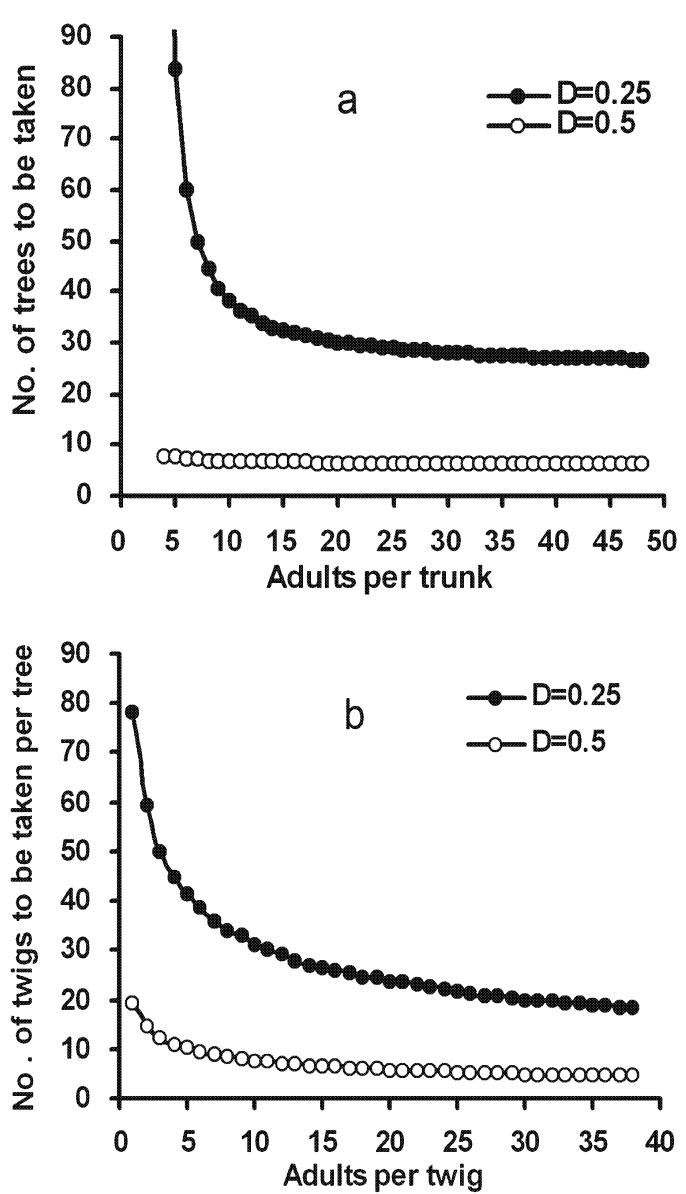

Fig. 2. Optimal number of trunks to be sampled for estimating population density of Corythucha ciliata with reliability levels of $D=0.25$ and $D=0.50$. - a. Overwintering adults. $-\mathrm{b}$. Wandering adults.

level of 0.25 or 0.5 would require the sampling of 35 or 7 trunks, respectively (Fig. 2a).

In the wandering stage, the Taylor's power law regression fit the data better than Iwao's patchiness regression, and the optimal sample size was therefore determined by Taylor's power law. The $a$ and $b$ indices of the sampling target twigs were 1.82 and 1.60 , respectively. Based on Equation (6), the optimal number of trunks that should be sampled for a given number of wandering adults is indicated in Fig. 2b. According to a recent study, 38 wandering adults per twig caused serious damage ( $\mathrm{Ju}$ et al. 2010b). Based on TRSGPP in 2007, controls should be applied when there are 10 wandering adults per trunk (38/4). In Shanghai, therefore, estimating the number of wandering adults per trunk with a precision level of 0.25 or 0.5 would require the sampling of 32 or 8 trunks, respectively (Fig. 2b).

\section{Discussion}

Many researchers have used Iwao's or Taylor's equations to determine the distribution pattern of insect pests in crops (Taylor 1961, Iwao 1968, Peng \& Brewer 1994, Jiang et al. 1995, Xue et al. 2000, Hsu et al. 2001, Wang et al. 2006, Wang 2011). In this study of C. ciliata, both Iwao's and Taylor's indices of dispersion were $>1$, suggesting (see Southwood 1978) that this pest has an aggregated distribution among and within $P . \times$ acerifolia trees. Clumped or aggregated distribution patterns were detected when the pest was highly active in its wandering stage between July and August and also when it was inactive in its overwintering stage between February and March. Öszi et al. (2005) reported that $C$. ciliata nymphs were spatially aggregated, while the adults tended to have more uniform and balanced distribution patterns.

According to Vasic (1975) and Battisti et al. (1985), the overwintering adults prefer the lower parts of the trunk (under $4.8 \mathrm{~m}$ of an 11 to $16 \mathrm{~m}$ high trunk), and most overwintering adults occur under the bark on the northeast and northwest side of the trunk. Our investigation demonstrated that, in addition to the trunks, the branches near the trunk were suitable overwintering sites for adults. A previous study determined that the wandering stage of $C$. ciliata mainly damages the lower crown of the tree, and the author inferred that the wandering adults were therefore distributed mainly in the lower crown (Zangheri 1984). In the current study, in contrast, the densities of the wandering stages of $C$. ciliata on twigs did not differ with crown layer (upper vs. lower) or direction. This difference in results may be due to differences in environmental conditions between the two regions.

Corythucha ciliata mainly infests Platanus occidentalis L. in its native land, North America (Halbert \& Meeker 1998), but prefers to feed on $P$. $\times$ acerifolia in China. Because $C$. ciliata has seriously damaged $P . \times$ acerifolia in Shanghai, we are now trying to reduce its number and slow 
its spread by insecticide application. Large-scale application of insecticides, however, would be environmentally undesirable, especially in the commercial districts where the London plane trees grow. Hence, pesticide applications must be restricted in space and time. By indicating effective methods for sampling $C$. ciliata on London plane trees, the results in this paper should help pest managers determine when pesticides or other control should be applied. The results should also indicate where pesticides should be applied. For example, the results showed that most overwintering $C$. ciliata adults occurred on the trunk and on the branches near the trunk. It follows that, in winter, insecticides could be restricted to these parts of the tree. In the wandering stage, however, adults and nymphs on twigs are aggregated but not related to crown layer or directions. During the wandering period, therefore, all twigs should be sprayed with insecticides. The results presented here should also help with assessing the efficacy of $C$. ciliata control.

Corythucha ciliata has natural predators, including bedbugs, spiders, crickets, locusts (Arzone 1984), and pathogens, including viruses, nematodes, and fungi (Sidor 1985). In urban areas, biological control would be preferred to chemical ones, because it would likely be less harmful to humans and other non-target organisms. As with application of insecticides, application of biological control agents could benefit from the results of this study in deciding when treatments are needed and which parts of trees should be treated.

Although we investigated $C$. ciliata populations during two periods (corresponding to the insect's overwintering and wandering stages), $C$. ciliata has five generations per year in the Yangze River basin of China (Xiao et al. 2010). For a more complete understanding of the spatial distribution of C. ciliata and of the sampling methods required to describe that distribution, the pest should be sampled at monthly intervals during periods of high and low activity.

Acknowledgements. This research was financially supported by the Key Project of Science and Technology Commission of Shanghai Municipality (Grant No. 10JC1414100), the Shanghai Rising-Star Program (type A) (Grant No. 1 1QA1406000), and the Research Program of Yangzhou Science \& Technology Bureau (Grant No. YZ2010064).

\section{References}

Arzone, A. 1984: Spreading and importance of Corythucha ciliata (Say) in Italy twenty years later. - Bulletin of the International Union of Biological Sciences, West Palaearctic Regional Section IX: 1.

Balarin, I. \& Maceljski, M. 1986a: The results of investigations on Corythuca ciliata. - Bulletin of the International Organisation for Biological Control, West Palaearctic Regional Section IX: 11-19.

Balarin, I. \& Maceljski, M. 1986b: Some new results of investigations on the biology and ecology of Corythuca ciliata. II Meeting WG "Integrated Control of C. ciliata" Padova, 1985. - Bulletin of the International Organisation for Biological Control, West Palaearctic Regional Section IX: 48-52.

Battisti R., Forti, A. \& Zaugheri, S. 1985: Research on biology of sycamore lace bug Corythucha ciliata (Say) (Rhynchota Tingidae) in the Veneto regions. - Frustula Entomologica 7/8: 125-141.

Bechinski, E. J. \& Pedigo, L. P. 1981: Population dispersion and development of sampling plans of Orius insidiosus and Nabis spp. in soyabeans. - Environmental Entomology 10: 835-841.

Chen, G. B., Wang, F., Feng, C. J. \& Ju, R. T. 2011: Efficacy tests of six kinds of pesticides for controlling Corythucha ciliata. - Jiangsu Agricultural Sciences 39(3): 125-128. [In Chinese; English abstract.]

Cheol, S. \& Kwang, Y. C. 2000: Ecological characteristics and insecticidal susceptibility of sycamore lace bug Corythucha ciliata (Say) (Hemiptera: Tingidae). Korean Journal of Life Science 10: 164-168.

Chung, Y. J., Kwon, T. S., Yeo, W. H., Byun, B. K. \& Park, C. H. 1996: Occurrence of the sycamore lace bug, Corythucha ciliata (Say) (Hemiptera: Tingidae) in Korea. - Korean Journal of Applied Entomology 35: 137-139.

Halbert, S. E. \& Meeker, J. R. 1998: The sycamore lace bug, Corythucha ciliata (Say) (Hemiptera: Tingidae). - Florida Department of Agriculture and Consumer Services, Division of Plant Industry, Entomology Circular 387: 1-2.

Hsu, J. C., Horng, S. B., \& Wu, W. J. 2001: Spatial distribution and sampling of Aulacaspis yabunikkei (Homoptera: Diaspididae) in camphor trees. - Bulletin of Taiwan Society of Plant Protection 43: 69-81.

Iwao, S. 1968: A new regression method for analyzing the aggregation pattern of animal populations. - Researches on Population Ecology 10: 1-20.

Iwao, S. \& Kuno, E. 1968: Use of the regression of mean crowding on mean density for estimating sample size and the transformation of data for the analysis of variance. - Researches on Population Ecology 10: 210 214.

Jasinka, J. 1981: Pyrethroidok a platán csipkéspoloska (Corythucha ciliata) elleni küzdelemben. - Növényvédelem 17: 302-303. [In Hungarian.]

Jasinka, J., \& Bozsits, G. 1977: A platán csipkéspoloska 
(Corythucha ciliata) fellépése Magyarországon. Növényvédelem 13: 42-46. [In Hungarian.]

Jiang, J., Huang, G. P., Liu, Q. S. \& Mao, H. P. 1995: Study on Phlossa jianningana. - Scientia Silvae Sinicae 31: 513-519. [In Chinese; English abstract.]

Ju, R. T., Li, Y. Z., Wang, F. \& Du, Y. Z. 2009: Spread of an exotic species, Corythucha ciliata (Say, 1832), in China (Hemiptera: Tingidae). — Entomological News 120: 409-414.

Ju, R. T. \& Li, B. 2010: Sycamore lace bug, Corythuch a ciliata, an urban invasive alien pest rapidly spreading in China. - Biodiversity Science 18: 638-646. [In Chinese; English abstract.]

Ju, R. T., Xiao, Y. Y., Xue, G. S., Wang, F., Li, Y. Z. \& Du, Y. Z. 2010a: Host range test of Corythucha ciliata (Say). - Chinese Bulletin of Entomology 47: 558 562. [In Chinese; English abstract.]

Ju, R. T., Wang, F. \& Li, B. 2010b: Leaf physiological responses in the London plane tree (Platanus $\times$ acerifolia) (Platanaceae) to injury by the sycamore lace bug, Corythucha ciliata (Hemiptera: Tingidae). - Acta Entomologica Sinica 53: 1009-1014. [In Chinese; English abstract.]

Ju, R. T., Xiao, Y. Y., Wang, F. \& Li, B. 2010c: Supercooling capacity and cold hardiness of the adults of the sycamore lace bug, Corythucha ciliata (Hemiptera: Tingidae). - CryoLetters 31: 445-453.

Ju, R. T., Wang, F. \& Li, B. 2011 a: Effects of temperature on the development and population growth of the sycamore lace bug, Corythucha ciliata. - Journal of Insect Science 11.16. Available from: http://insectscience.org/11.16/. (Site visited on 2 Nov, 2009).

Ju, R. T., Chen, G. B., Wang, F. \& Li, B. 2011 b: Effects of heat shock, heat exposure pattern, and heat hardening on survival of the sycamore lace bug, Corythucha ciliata (Say) (Hemiptera: Tingidae). — Entomologia Experimentalis et Applicata 41: 168-177.

Ju, R. T., Xiao, Y. Y. \& Li, B. 2011c: Rapid cold hardening increases cold and chilling tolerances more than acclimation in the adults of the sycamore lace bug, Corythucha ciliata (Say) (Hemiptera: Tingidae). — Journal of Insect Physiology 57: 1577-1582.

Kuno, E. 1969: A new method of sequential sampling to obtain the population estimates with a field level of precision. - Researches on Population Ecology 11: $127-136$.

Li, S. Q., Dong, L. K., Xia, W. S. \& Zhang, G. A. 2008: Occurrence of Corythucha ciliata and its control. Hubei Plant Protection (1): 12-13. [In Chinese.]

Lloyd, M. 1967: Mean crowding. - Journal of Animal Ecology 36: 1-30.

Maceljski, M. 1986: Current status of Corythuca ciliata in Europe. - Bulletin Oral English Proficiency Program/European Plant Protection Organization Bulletin 16: 621-624.

Mizuno, T., Kondo, K., Tanaka, K., Okahara, Y. \& Deguchi, K. 2004: The life cycle of the sycamore lace bug Corythucha ciliata (Say) (Heteroptera: Tingidae) on
Platanus spp. in Nagoya city. - Research Bulletin of the Plant Protection Service Japan 40: 141-143.

Mutun, S. 2009: Corythucha ciliata, a new Platanus pest in Turkey. - Phytoparasitica 37: 65-66.

Peng, C. \& Brewer, G. J. 1994: Spatial distribution of the red sunflower seed weevil (Coleoptera: Curculionidae) on sunflower. - Environmental Entomology 23: 1101-1105.

Reiderné S. \& Ripka, G. 1990: A platán csipkéspoloska (Corythucha ciliata Say) biológiája és az ellene való védekezés lehetőségei. — Növényvédelem 26: 36-40. [In Hungarian.]

Sidor, C. 1985: Micro-organisms pathogenic for Insects till now found in Corythuch a ciliata. - Bulletin of the International Union of Biological Sciences, West Palaearctic Regional Section IX: 72.

Southwood, T. R. E. 1978: Ecological methods. - Chapman and Hall, London. pp. 524.

SPSS. 2006: SPSS Base 15.0 Edition for Windows User's Guide. - SPSS Inc., Chicago.

Streito, J. C. 2006: Note sur quelques espe 'ces envahissantes de Tingidae: Corythucha ciliata (Say, 1932), Stephanitis pyrioides (Scott, 1874) et Stephanitis takeyai Drake \& Maa, 1955 (Hemiptera: Tingidae). — Entomologiste $62: 31-36$.

Taylor, L. R. 1961: Aggregation, variance and the mean. Nature 189: 732-735.

Taylor, L. R. 1984: Assessing and interpreting the spatial distribution of insect population. - Annals of the Entomological Society of America 29: 321-358.

Vasic, M. 1975: Control of Corythucha ciliata on Platanus spp. in avenues and parks in Belgrade. - Sumarstvo 28: 59-64.

Wang, F. 2011: Spatial distribution of hibernating eggs of Mansoniella cinnamomi. - Journal of Zhejiang Forestry Science \& Technology (5): 1116-1119. [In Chinese; English abstract.]

Wang, F., Ju, R. T., Li, Y. Z. \& Du, Y. Z. 2006: Spatial distribution of hibernating cocoon of Parasa consocia on different plants. - Acta Agriculturae Zhejiangensis $18: 448-452$.

Wicki, C. 1984: Trials againts Corythucha ciliata in Basel. - Bulletin of the International Union of Biological Sciences, West Palaearctic Regional Section IX: 37.

Wilson, L. T. \& Room, P. M. 1982: The relative efficiency and reliability of three methods for sampling arthropods in Australian cotton fields. - Journal of the Australian Entomological Society 21: 175-181.

Xia, W. S., Liu, C., Dong, L. K. \& Ou, K. F. 2007: Occurrence and biology of Corythuch a ciliata. - Plant Protection 33: 142-145. [In Chinese.]

Xiao, Y. Y., Wang, F., Ju, R. T. \& Li, Y. Z. 2010: Life history and occurrence of Corythucha ciliata in Shanghai. - Chinese Bulletin of Entomology 47: 404408. [In Chinese; English abstract.]

Xue, Z. G., Wang, Y. C. \& Zhang, Y. Z. 2000: A study on the spatial pattern of the larva of Thosea sinensis surviving in winter. - Journal of Jiangsu Forestry Science \& Technology 27: 43-45. [In Chinese; English abstract.] 
Yamamura, K. 2000: Colony expansion model for describing the spatial distribution of populations. - Population Ecology 42:161-169.

Zangheri, S. 1984: Syntheses des observations sur la biologie de la Corythucha ciliata. - Bulletin of the International Union of Biological Sciences, West Palaearctic Regional Section IX: $349-358$.
Öszi, B., Lanányi, M. \& Hufnagel, L. 2005: Population dynamics of the sycamore lace bug in Hungary. - Applied Ecology and Environmental Research 4: 135150. 